Pacific Journal of Mathematics

ZERO-ONE MATRICES WITH ZERO TRACE 


\section{ZERO-ONE MATRICES WITH ZERO TRACE}

\section{R. FULKERSON}

Summary. General existence conditions for an $n \times n$ zero-one matrix having given row and column sums and zero trace consist of a set of $2^{n}-1$ inequalities. These are shown to simplify to the following set of $n$ inequalities in case the row sums $a_{i}$ and column sums $b_{i}$ satisfy $a_{1} \geq \cdots \geq a_{n}, b_{1} \geq \cdots \geq b_{n}$ :

$$
\sum_{i=1}^{k} b_{i} \leq \sum_{i=1}^{k} a_{i}^{* *} \quad(k=1, \cdots, n),
$$

where $a_{j}^{* *}$ is the number of $a_{i}$ such that $i<j$ and $a_{i} \geq j-1$ plus the number of $a_{i}$ such that $i>j$ and $a_{i} \geq j$.

Introduction. Ryser [5] and Gale [3] have established simple arithmetic conditions that are necessary and sufficient for the existence of a matrix of zeros and ones having prescribed row and column sums. Here we vary the problem slightly and look for conditions under which there will be an $n \times n$ matrix of zeros and ones having given row and column sums and zero trace. While it is not difficult to derive such conditions from known feasibility theorems for network flows, they appear not to simplify greatly except under special circumstances.

One motivation for considering this problem lies in a graph theoretical interpretation. The existence problem for a directed, loopless graph on $n$ nodes having given local degrees (i.e., for each node two non-negative integers are given, the first specifying the number of issuing arcs, the second the number of entering arcs, and arcs leading from a node to itself are not allowed) is equivalent to that for a zero-one matrix having given row and column sums and zero trace.

1. General existence conditions. Let

$$
\begin{gathered}
a_{1}, a_{2}, \cdots, a_{n} \\
b_{1}, b_{2}, \cdots, b_{n}
\end{gathered}
$$

be given non-negative integers. We seek conditions under which the constraints

$$
\begin{array}{ll}
\sum_{j=1}^{n} x_{i j} \leq a_{i} & (i=1, \cdots, n) \\
\sum_{i=1}^{n} x_{i j} \geq b_{j} & (j=1, \cdots, n)
\end{array}
$$

Received September 21, 1959. 


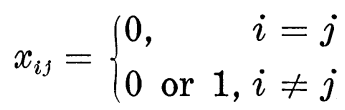

have a solution $x_{i j}$. Thus if $\sum a_{i}=\sum b_{i}$, we are looking for an $n \times n$ matrix having row sums $a_{i}$, column sums $b_{i}$, and zero trace.

Feasibility conditions for the constraints (1) can be deduced, for example, either from known results on the subgraph problem for directed graghs [4, 2], or from the supply-demand theorem [3] for network flows. We shall use the latter.

Applied to our problem, the supply-demand theorem and the integrity theorem for network flows $[1,2]$ assert that the constraints (1) are feasible if and only if, corresponding to each non-empty subset $I \subseteq\{1, \cdots, n\}$ of columns, the "aggregate demand" $\sum_{I} b_{i}$ of $I$ can be fulfilled without violating the "supply" limitations (1a) on individual rows, or the "capacity" constraints (1c) on individual cells of the matrix. Thus, for each $I$ we need to determine the maximal number of ones that can be placed in the columns corresponding to $I$ (ignoring all other columns), subject to the restrictions that at most $a_{i}$ ones can be used from the $i$ th row, and no ones can be put along the main diagonal. It, follows that the maximal number of ones that can be put in the $I$ columns is given by

$$
\sum_{I} \min \left(a_{i},|I|-1\right)+\sum_{\bar{I}} \min \left(a_{i},|I|\right)
$$

where $|I|$ denotes the number of indices in $I$ and $\bar{I}$ is the complement of $I$ in $\{1, \cdots, n\}$. Consequently feasibility conditions for (1) are

$$
\sum_{I} b_{i} \leq \sum_{I} \min \left(a_{i},|I|-1\right)+\sum_{\bar{I}} \min \left(a_{i},|I|\right),
$$

for all non-empty $I \subseteq\{1, \cdots, n\}$, a set of $2^{n}-1$ inequalities.

If we let $N=\{1, \cdots, n\}$ and define, for $I \subseteq N$ and each $k=1, \cdots, n$,

$$
a_{k}^{*}(I)=\mid\left\{i \mid i \in I \text { and } a_{i} \geq k\right\} \mid,
$$

then (2) may be written as

$$
\sum_{I} b_{i} \leq \sum_{i=1}^{|I|-1} a_{i}^{*}(N)+a_{|I|}^{*}(\bar{I})
$$

(A convenient way to see this is to represent the integers $a_{i}$ by rows of dots. For example, if in Figure 1 we take $I=\{2,4,5\}$, then the right side of (2) is given by the number of dots lying to the left of the indicated line. On the other hand, since $a_{k}^{*}(I)$ is the number of dots in the $k$ th column that also lie in the $I$-rows, the first term on the right of (4) counts all dots in the first $|I|-1=2$ columns, and the second term counts the remaining dots that lie to the left of the line.) 


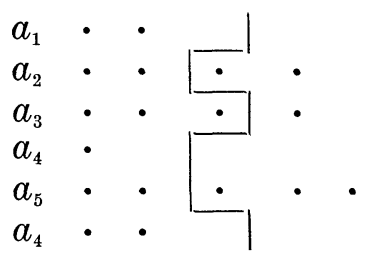

Fig. 1

Henceforth we shall let

$$
a_{k}^{*}=a_{k}^{*}(N),
$$

retaining the functional notation only when proper subsets of $N$ are being considered. The sequence $\left(a_{i}^{*}\right)$ is called the conjugate sequence to $\left(a_{i}\right)$; it does not depend on the ordering of the $a_{i}$. In the next section we shall make use of another sequence $\left(a_{i}^{* *}\right)$ that will depend on the ordering of the $a_{i}$.

2. Simplification of existence conditions for $a$ 's and $b$ 's that are monotone together. The inequalities (4) simplify considerably if we assume that

$$
\begin{aligned}
& a_{1} \geq a_{2} \geq \cdots \geq a_{n} \geq 0, \\
& b_{1} \geq b_{2} \geq \cdots \geq b_{n} \geq 0,
\end{aligned}
$$

or, what is the same thing, if there is some common renumbering for which (5) holds.

For if (5) holds, and if we rewrite (4) as

$$
\sum_{I} b_{i}-a_{|I|}^{*}(\bar{I}) \leq \sum_{i=1}^{|I|-1} a_{i}^{*}
$$

it is apparent that the left side of (6) is maximized, over all $I$ with $|I|=k$, by selecting $I=\{1, \cdots, k\}$, because this $I$ simultaneously maximizes $\sum_{I} b_{i}$ and minimizes $a_{k}^{*}(\bar{I})$. Since the right side of (6) depends only on $|I|$, it follows that the $2^{n}-1$ inequalities (6) are equivalent, under the assumption (5), to the $n$ inequalities

$$
\sum_{i=1}^{k} b_{i} \leq \sum_{i=1}^{k-1} a_{i}^{*}+a_{k}^{*}(\{k+1, \cdots, n\}), \quad k=1, \cdots, n
$$

The right side of (7) has a convenient and natural interpretation, again in terms of rows of dots, except that this time no dots are placed in the main diagonal of the schema. (See Figure 2.) 


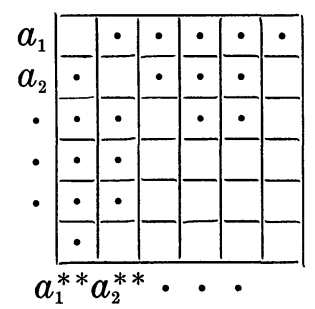

Fig. 2

If we define, for $k=1, \cdots, n$, the sets of indices

$$
\begin{aligned}
& I_{k}=\left\{i \mid i<k \text { and } a_{i} \geq k-1\right\} \\
& J_{k}=\left\{i \mid i>k \text { and } a_{i} \geq k\right\},
\end{aligned}
$$

and let

$$
a_{k}^{* *}=\left|I_{k}\right|+\left|J_{k}\right|,
$$

so that $a_{k}^{* *}$ is the number of dots in the $k$ th column of the diagonally restricted array of dots, we see that the right side of (7) is just $\sum_{i=1}^{k} a_{i}^{* *}$. Consequently feasibility conditions are simply that the partial sums of the sequence $\left(b_{i}\right)$ be dominated by those of the sequence $\left(a_{i}^{* *}\right)$, and we have conditions analogous to those found by Ryser and Gale for the case in which ones can be placed along the main diagonal.

We shall refer to the sequence $\left(a_{i}^{* *}\right)$ defined by (8) and (9) as the diagonally restricted conjugate of $\left(a_{i}\right)$ in the statement of the following theorem.

THEOREM. Let $a_{i}, b_{i}(i=1, \cdots, n)$ be monotone non-increasing sequences of non-negative integers. Then the following are equivalent:

(i) There is an $n \times n$ matrix of zeros and ones with zero trace whose $i$ th row [column] sum is bounded above [below] by $a_{i}\left[b_{i}\right]$;

(ii) $\sum_{i=1}^{k} b_{i} \leq \sum_{i=1}^{k} a_{i}^{* *},(k=1, \cdots, n)$, where the sequence $\left(a_{i}^{* *}\right)$ is the diagonally restricted conjugate of $\left(a_{i}\right)$.

Particular cases under which the rows and columns of the matrix can be rearranged so that the theorem applies are if the row sum upper bounds are constant, or if the column sum lower bounds are constant. In each of these cases, the obvious necessary conditions for feasibility turn out to be sufficient.

3. Constant row or column sum bounds. Unlike the sequence $\left(a_{i}^{*}\right)$, the sequence $\left(a_{i}^{* *}\right)$ is not necessarily monotone (see Figure 2), but, as we shall prove in the following lemma, it is almost so, provided the $a_{i}$ are monotone. Here the phrase "almost monotone" means that the sequence is either monotone or else it has at most one point of increase, and that increase is one. We shall make use of this fact in the proof of Corollary 1 below. First we state and prove the lemma. 
LEMmA. If $a_{1} \geq a_{2} \geq \cdots \geq a_{n}$, then the diagonally restricted conjugate sequence $\left(a_{i}^{* *}\right)$ is either monotone non-increasing or else, for some $k=1, \cdots, n-1$,

$$
a_{1}^{* *} \geq \cdots \geq a_{k}^{* *} ; a_{k+1}^{* *}=a_{k}^{* *}+1 \geq a_{k+2}^{* *} \geq \cdots \geq a_{n}^{* *} .
$$

Proof. It follows from (8) that

$$
\begin{gathered}
\left|I_{k}\right| \geq\left|I_{k+1}\right|-1 \\
\left|J_{k}\right| \geq\left|J_{k+1}\right|
\end{gathered}
$$

and hence from (9) that

$$
a_{k}^{* *} \geq a_{k+1}^{* *}-1
$$

equality holding if and only if $\left|I_{k}\right|=\left|I_{k+1}\right|-1,\left|J_{k}\right|=\left|J_{k+1}\right|$. Moreover, since $a_{1} \geq \cdots \geq a_{n}$, we have

$$
a_{k}^{* *}=a_{k+1}^{* *}-1
$$

if and only if $a_{k} \geq k$ and $a_{k+1}<k$. Thus, if there were two points of increase in the sequence $\left(a_{i}^{* *}\right)$, say $k$ and $l$ with $k<l$, then we should have

$$
a_{l} \geq l>k>a_{k+1},
$$

contradicting $a_{k+1} \geq a_{l}$. This completes the proof of the lemma.

COROLlaRY 1. There is an $n \times n$ zero-one matrix with zero trace whose column sums are bounded below by $b$, and whose $i^{\text {th }}$ row sum is bounded above by $a_{i}$, if and only if $n b \leq \sum_{1}^{n} a_{i}^{* *}$, where $\left(a_{i}^{* *}\right)$ is the diagonally restricted conjugate of a monotone non-increasing rearrangement of $\left(a_{i}\right)$.

Proof. By effecting a rearrangement of rows and the same rearrangement of columns, we may assume $a_{1} \geq a_{2} \geq \cdots \geq a_{n}$ and hence apply the theorem. Thus, necessity being obvious, we need to show that the inequalities

$$
k b \leq \sum_{1}^{k} a_{i}^{* *} \quad(k=1, \cdots, n)
$$

follow from $n b \leq \sum_{1}^{n} a_{i}^{* *}$. This can be established by induction on $n$, as follows. For $n=1$, there is nothing to prove. Assume the proposition for $n-1$ and consider the case for $n$. If $b<a_{n}^{* *}$, then the lemma, together with the fact that we are dealing with integers, implies that $b \leq a_{i}^{* *}$ for all $i$. Consequently 


$$
k b \leq \sum_{i=1}^{k} a_{i}^{* *}
$$

If, on the other hand, $b \geq a_{n}^{* *}$, then

$$
(n-1) b \leq \sum_{i=1}^{n-1} a_{i}^{* *},
$$

and the induction hypothesis applies.

COROLlaRY 2. There is an $n \times n$ zero-one matrix with zero trace whose row sums are bounded above by $a$, and whose $i^{\text {th }}$ column sum is bounded below by $b_{i}$, if and only if $\sum_{i=1}^{n} b_{i} \leq n a, b_{i} \leq n-1$.

Proof. Again necessity is obvious. To prove sufficiency, we need to show that $\sum_{i=1}^{n} b_{i} \leq n a$ and $b_{i} \leq n-1$ imply

$$
\sum_{i=1}^{k} b_{i} \leq \sum_{i=1}^{k} a_{i}^{* *}
$$

where $b_{1} \geq \cdots \geq b_{n}$. If $k \leq a$, then $a_{i}^{* *}=n-1$ for $i \leq k$, and hence

$$
\sum_{i=1}^{k} b_{i} \leq k(n-1)=\sum_{1}^{k} a_{i}^{* *}
$$

If, on the other hand, $k>a$, then

$$
a_{i}^{* *}= \begin{cases}n-1 & \text { for } i \leq a \\ a & \text { for } i=a+1 \\ 0 & \text { for } i>a+1,\end{cases}
$$

and hence

$$
\sum_{i=1}^{k} b_{i} \leq \sum_{i=1}^{n} b_{i} \leq n a=\sum_{i=1}^{k} a_{i}^{* *}
$$

\section{REFERENCES}

1. L. R. Ford, Jr., and D. R. Fulkerson, A simple algorithm for finding maximal network flows and an application to the Hitchock problem, Can J. Math., 9 (1957), 210-218.

2. D. R. Fulkerson, A network flow feasibility theorem and combinatorial applications Can. S. Math., 11 (1959), 440-451.

3. D. Gale, A theorem on flows in networks, Pacific J. Math., 7 (1957), 1073-1082.

4. O. Ore, Studies on directed graphs I, Ann. of Math., 63 (1956), 383-406.

5. H. J. Ryser, Combinatorial properties of matrices of zeros and ones, Can. J. Math., 9 (1957), 371-377.

The RAND CORPORATION 


\section{PACIFIC JOURNAL OF MATHEMATICS}

\section{EDITORS}

\author{
David Gilbarg \\ Stanford University \\ Stanford, California \\ F. H. Brownell \\ University of Washington \\ Seattle 5 , Washington
}

\author{
A. L. Whiteman \\ University of Southern California \\ Los Angeles 7, California \\ L. J. PAIGE \\ University of California \\ Los Angeles 24, California
}

\section{ASSOCIATE EDITORS}

\author{
E. F. BECKENBACH \\ T. M. CHERRY \\ D. DERRY
}
E. HEWITT
A. HORN
L. NACHBIN
M. OHTSUKA
H. L. ROYDEN
M. M. SCHIFFER

E. SPANIER

E. G. STRAUS

F. WOLF

\section{SUPPORTING INSTITUTIONS}

\author{
UNIVERSITY OF BRITISH COLUMBIA \\ CALIFORNIA INSTITUTE OF TECHNOLOGY \\ UNIVERSITY OF CALIFORNIA \\ MONTANA STATE UNIVERSITY \\ UNIVERSITY OF NEVADA \\ NEW MEXICO STATE UNIVERSITY \\ OREGON STATE COLLEGE \\ UNIVERSITY OF OREGON \\ OSAKA UNIVERSITY \\ UNIVERSITY OF SOUTHERN CALIFORNIA
}

\author{
STANFORD UNIVERSITY \\ UNIVERSITY OF TOKYO \\ UNIVERSITY OF UTAH \\ WASHINGTON STATE COLLEGE \\ UNIVERSITY OF WASHINGTON

AMERICAN MATHEMATICAL SOCIETY
CALIFORNIA RESEARCH CORPORATION
HUGHES AIRCRAFT COMPANY
SPACE TECHNOLOGY LABORATORIES
NAVAL ORDNANCE TEST STATION

Mathematical papers intended for publication in the Pacific Journal of Mathematics should be typewritten (double spaced), and the author should keep a complete copy. Manuscripts may be sent to any one of the four editors. All other communications to the editors should be addressed to the managing editor, L. J. Paige at the University of California, Los Angeles 24, California. ..

50 reprints per author of each article are furnished free of charge; additional copies may be obtained at cost in multiples of 50 .

The Pacific Journal of Mathematics is published quarterly, in March, June, September, and December. The price per volume (4 numbers) is $\$ 12.00$; single issues, $\$ 3.50$. Back numbers are available. Special price to individual faculty members of supporting institutions and to individual members of the American Mathematical Society: $\$ 4.00$ per volume; single issues, $\$ 1.25$.

Subscriptions, orders for back numbers, and changes of address should be sent to Pacific Journal of Mathematics, 2120 Oxford Street, Berkeley 4, California.

Printed at Kokusai Bunken Insatsusha (International Academic Printing Co., Ltd.), No. $6_{4}$ 2-chome, Fujimi-cho, Chiyoda-ku, Tokyo, Japan.

PUBLISHED BY PACIFIC JOURNAL OF MATHEMATICS, A NON-PROFIT CORPORATION

The Supporting Institutions listed above contribute to the cost of publication of this Journăl, but they are not owners or publishers and have no responsibility for its content or policies. 


\section{Pacific Journal of Mathematics}

\section{Vol. 10, No. $3 \quad$ November, 1960}

Glen Earl Baxter, An analytic problem whose solution follows from a simple

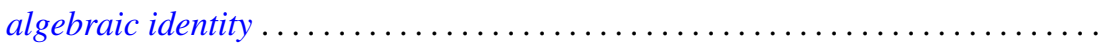

Leonard D. Berkovitz and Melvin Dresher, A multimove infinite game with linear payoff. .

Earl Robert Berkson, Sequel to a paper of A. E. Taylor ......................

Gerald Berman and Robert Jerome Silverman, Embedding of algebraic systems.... 767

Peter Crawley, Lattices whose congruences form a boolean algebra . . . . . ...... 777

Robert E. Edwards, Integral bases in inductive limit spaces . . . . . . . . . . . . . . .

Daniel T. Finkbeiner, II, Irreducible congruence relations on lattices . . . . . . . . . .

William James Firey, Isoperimetric ratios of Reuleaux polygons . . . . . . . . . . . 787

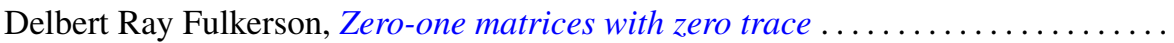

Leon W. Green, A sphere characterization related to Blaschke's conjecture........

Israel (Yitzchak) Nathan Herstein and Erwin Kleinfeld, Lie mappings in

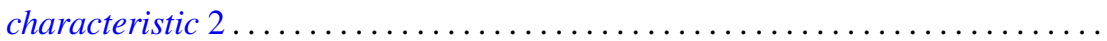

Charles Ray Hobby, A characteristic subgroup of a $p$-group .................

R. K. Juberg, On the Dirichlet problem for certain higher order parabolic

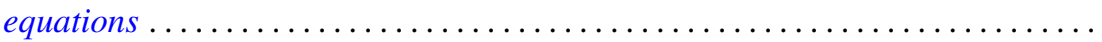

Melvin Katz, Infinitely repeatable games ......................

Emma Lehmer, On Jacobi functions . . . . . . . . . . . . . . . . . . . . . . . . .

D. H. Lehmer, Power character matrices

Henry B. Mann, A refinement of the fundamental theorem on the density of the sum of two sets of integers.

Marvin David Marcus and Roy Westwick, Linear maps on skew symmetric matrices: the invariance of elementary symmetric functions . .

Richard Dean Mayer and Richard Scott Pierce, Boolean algebras with ordered

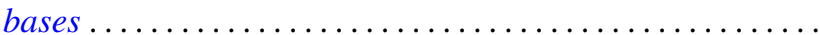

Trevor James McMinn, On the line segments of a convex surface in $E_{3} \ldots$

Frank Albert Raymond, The end point compactification of manifolds ..

Edgar Reich and S. E. Warschawski, On canonical conformal maps of regions of arbitrary connectivity

Marvin Rosenblum, The absolute continuity of Toeplitz's matrices...

Lee Albert Rubel, Maximal means and Tauberian theorems . .

Helmut Heinrich Schaefer, Some spectral properties of positive linear operators

Jeremiah Milton Stark, Minimum problems in the theory of pseudo-conformal transformations and their application to estimation of the curvature of the invariant metric.

Robert Steinberg, The simplicity of certain groups ...

Hisahiro Tamano, On paracompactness. .

Angus E. Taylor, Mittag-Leffler expansions and spectral theory .

Marion Franklin Tinsley, Permanents of cyclic matrices ...... . 